\title{
Kinetic studies on oxidative coupling of methane to ethylene over catalysts supported by mixed-oxides
}

\author{
Kalyani Miriyala* and Bala Krishna Inguva \\ Department of Chemical Engineering, Chaitanya Bharathi Institute of Technology, Hyderabad, India
}

Received: 13-March-2019; Revised: 23-April-2019; Accepted: 25-April-2019

C2019 Kalyani Miriyala and Bala Krishna Inguva. This is an open access article distributed under the Creative Commons Attribution (CC BY) License, which permits unrestricted use, distribution, and reproduction in any medium, provided the original work is properly cited.

\begin{abstract}
A main component in producing ethylene from natural is methane. By using oxidative coupling of methane (OCM) reaction is a promising route. Catalytic tubular reactors are found to have advantages in terms of oxygen supply to the catalyst. To achieve this objective, a unified time-independent one-dimensional pseudo-homogeneous model is developed. Changing the inlet conditions, the sensitivity of the proposed model is analysed. Investigations were made in terms of parametric sensitivity and fixed bed reactor response by changing inlet flow velocities, concentrations and temperatures. The kinetic data of the reactions involved were estimated using linear regression. The effect of variables like, methane flow velocities, operating conditions, temperature, properties of catalysts on methane conversion and yield are studied from simulation results. All the feasible reactions for OCM are included in the proposed scheme of the reactions. The present work combines reaction engineering aspects with the experimental kinetic results previously obtained to predict OCM reactor performance under various operating conditions. Model equations are solved using the Runge Kutta method. The simulated results using the proposed kinetic model matched the experimental results of OCM reaction within a deviation range of $\pm 20 \%$.
\end{abstract}

\section{Keywords}

Oxidative coupling of methane (OCM), Kinetic modelling, Mixed-oxide Catalyst, Conversion.

\section{Introduction}

Conversion of natural gas to useful chemicals can be achieved by a promising pathway Oxidative coupling of methane (OCM). Tubular reactors [1, 2] have limitations in applications, due to operating temperature around $1000 \mathrm{~K}$ and large heat production from the reaction and hence a rigorous design is required. This demands a thorough knowledge about the system's dynamics and careful reaction control. Nano-catalyst dense membrane reactors are also a viable alternative for performing the OCM reaction. Oxygen is continuously charged from the shell side of the reactor into a catalyst zone filled with catalyst to obtain a low concentration of local oxygen which improves reaction selectivity [3, 4]. Factors like rising prices of ethylene feedstock and greater demand for ethylene in global markets have driven investigators in the past thirty years to make significant efforts in finding economically feasible processes like OCM, for obtaining $\mathrm{C}_{2}$ hydrocarbons from methane.

\footnotetext{
*Author for correspondence
}

Due to comparatively low yields in OCM, the production of $\mathrm{C}_{2}$ hydrocarbons via this route is prohibited.

The following kinetic mechanisms are used extensively in the study of a variety of kinetic models of OCM to produce $\mathrm{C}_{2}$ hydrocarbons. Since the proposed mechanisms involve many chemical species, the kinetics of OCM reaction becomes complicated. Kinetic mechanisms of this reaction are mainly classified as [5-12]:

1) Gaseous phase reactions - kinetic simulation

2) Gaseous phase and surface reactionssimultaneous simulation

3) Kinetics of several radical reactions of single or many reactions

4) Methane consumption surface kinetics

5) Power law model rate expressions of $\mathrm{C}_{2+}$ and $\mathrm{CO}_{\mathrm{X}}$

6) Spectroscopic studies involving $\mathrm{O}^{-}$species and the reaction with methane 
Kinetic mechanisms proposed by Stansch et al. [7], Cheng and Shuai [13], Yaghobi and Ghoreishy [14], and Santamaria et al. [15] are in good consistency with experimental results.

One of the mechanisms proposed by Stansch et al. [7] is a comprehensive multistep mechanism consisting of ten steps. This model was proposed on the basis of kinetic measurements over a wide range of reaction conditions. The scheme of reaction has three primary and seven consecutive steps. Hougen-Watson (HW) types of rate expressions were used to describe the conversion of hydrocarbons and carbon monoxide with oxygen. The other reaction rates were described by the power law rate model. The conversions of methane and oxygen were determined experimentally by this kinetic model. Also, the yields of $\mathrm{C}_{2+}$ hydrocarbons and carbon oxides could be predicted with an average accuracy of $20 \%$.

Another simplified kinetic scheme of reaction for OCM was proposed by Yaghobi and Ghoreishy [14] over titaniate perovskite $\left(\mathrm{SnBaTiO}_{3}\right)$. Methane was considered to be converted in two parallel reactions by coupling reaction to $\mathrm{C}_{2}$, as a selective channel and by complete or partial oxidation to $\mathrm{CO}_{\mathrm{x}}$ as a nonselective step. The reaction rates of methane and the products are described by the power law model. Linear regression was used to determine the parameters in the model.

Cheng and Shuai [13] suggested a four lumped kinetic scheme that considered the catalytic reactions of methane, ethane and ethylene with oxygen as follows:

$$
\begin{aligned}
& \mathrm{CH}_{4}+2 \mathrm{O}_{2} \rightarrow \mathrm{CO}_{2}+2 \mathrm{H}_{2} \mathrm{O} \\
& 2 \mathrm{CH}_{4}+1 / 2 \mathrm{O}_{2} \rightarrow \mathrm{C}_{2} \mathrm{H}_{6}+\mathrm{H}_{2} \mathrm{O} \\
& \mathrm{C}_{2} \mathrm{H}_{6}+1 / 2 \mathrm{O}_{2} \rightarrow \mathrm{C}_{2} \mathrm{H}_{4}+\mathrm{H}_{2} \mathrm{O} \\
& \mathrm{C}_{2} \mathrm{H}_{4}+2 \mathrm{O}_{2} \rightarrow 2 \mathrm{CO}_{2}+2 \mathrm{H}_{2} \mathrm{O}
\end{aligned}
$$

Different kinetic expressions are available in literature that uses the power law to describe reaction rates [16, 17]. This simple yet practical category avoids the use of intermediates and any product formation rate can only be expressed as a function of the reactant concentrations. This method has its own advantages and disadvantages. The kinetics adopted in this study also follows a power law. Power law kinetics can be used for reactor simulations and it gives accurate results for reactor output. The drawback is that the detailed reaction mechanism involving components and radical interactions cannot be explained by this kind of equation.

Reactor analysis and modelling have been largely taken a setback due to the lack of reliable reaction kinetic that can account for the gas-phase homogeneous and heterogeneous reactions simultaneously.

1. The work reported in this study aimed at the development of comprehensive kinetics for the OCM that can be used for prediction of reactor performances under a wide range of operating conditions.

2. The kinetic model is proposed for a microcatalytic fixed-bed reactor (Figure1) over mixedoxide supported catalyst. This catalyst was found to be very active and exhibits high selectivity towards $\mathrm{C}_{2+}$ hydrocarbons.

3. On the basis of experimental data, the most suitable reaction network, rate equations, and kinetic parameters were determined.

4. The present study emphasizes on developing kinetics of OCM via the mechanistic approach, for the specified catalyst type and reactor configuration. The kinetic studies were performed assuming zero heat and mass transfer limitations.

\section{Model development}

Owing to some of the disadvantages of other reaction mechanisms mentioned in literature and to account for the detailed reaction mechanism of all possible reactions and radical interactions $\mathrm{LH}$ reaction mechanisms was proposed. The derivation of rate expressions for fluid-solid catalytic reaction is commonly done using Langmuir-HinshelwoodHougen-Watson (LHHW) model. The rate expression derived using this model, which simulates the surface phenomena during the process is preferred for the reactions involving solid catalysts. The primary reactions that affect the yield and selectivity of $\mathrm{C}_{2+}$ are the production of ethane from methane, consumption of ethylene and ethane by oxygen, water and carbon-dioxide. The reactions considered in OCM process are listed from Equations 1a to 3c. LH reaction mechanisms are shown in Equations 4-6. The equations for the changes in the components $\mathrm{CH}_{4}, \mathrm{C}_{2} \mathrm{H}_{4}, \mathrm{C}_{2} \mathrm{H}_{6}, \mathrm{CO}, \mathrm{CO}_{2}, \mathrm{H}_{2} \mathrm{O}$ and $\mathrm{O}_{2}$ along the reactor length are considered in Equations 7 and 8.

$$
\begin{array}{lll}
\mathrm{CH}_{4}+2 \mathrm{O}_{2} \rightarrow \mathrm{CO}_{2}+2 \mathrm{H}_{2} & (1 \mathrm{a}) & \mathrm{E}_{\mathrm{a}}=98.54 \\
\mathrm{CH}_{4}+\mathrm{H}_{2} \mathrm{O} \leftrightarrow \mathrm{CO}+3 \mathrm{H}_{2} & \text { (1b) } & \mathrm{E}_{\mathrm{a}}=240 \\
\mathrm{CH}_{4}+\mathrm{CO}_{2} \leftrightarrow 2 \mathrm{CO}+2 \mathrm{H}_{2} & \text { (1c) } & \mathrm{E}_{\mathrm{a}}=110 \\
2 \mathrm{CO}_{2}+2 \mathrm{H}_{2} \mathrm{O} \rightarrow \mathrm{C}_{2} \mathrm{H}_{4}+3 \mathrm{O}_{2} & \text { (2a) } & \mathrm{E}_{\mathrm{a}}=174.4
\end{array}
$$




$$
\begin{array}{lll}
2 \mathrm{CO}+4 \mathrm{H}_{2} \leftrightarrow \mathrm{C}_{2} \mathrm{H}_{4}+2 \mathrm{H}_{2} \mathrm{O} & (2 \mathrm{~b}) & \mathrm{E}_{\mathrm{a}}=394.2 \\
4 \mathrm{CO}+2 \mathrm{H}_{2} \leftrightarrow \mathrm{C}_{2} \mathrm{H}_{4}+2 \mathrm{CO}_{2} & (2 \mathrm{c}) & \mathrm{E}_{\mathrm{a}}=298.2 \\
2 \mathrm{CO}_{2}+3 \mathrm{H}_{2} \mathrm{O} \rightarrow \mathrm{C}_{2} \mathrm{H}_{6}+3.5 \mathrm{O}_{2} & (3 \mathrm{a}) & \mathrm{E}_{\mathrm{a}}=327.9 \\
2 \mathrm{CO}+5 \mathrm{H}_{2} \leftrightarrow \mathrm{C}_{2} \mathrm{H}_{6}+2 \mathrm{H}_{2} \mathrm{O} & (3 \mathrm{~b}) & \mathrm{E}_{\mathrm{a}}=360.1 \\
4 \mathrm{CO}+3 \mathrm{H}_{2} \leftrightarrow \mathrm{C}_{2} \mathrm{H}_{6}+2 \mathrm{CO}_{2} & \text { (3c) } & \mathrm{E}_{\mathrm{a}}=371.2
\end{array}
$$

Where

$\mathrm{R}$ - Rates of reaction

$\mathrm{K}$ - Equilibrium constant

$\mathrm{k}$ - Arrhenius constants

$\mathrm{E}_{\mathrm{a}}-$ Activation energy $(\mathrm{kJ} / \mathrm{mole})$

The kinetic model for the reaction network (1a-1c, $2 a-2 c$ and $3 a-3 c)$ uses LH reaction mechanisms for which rate equations are as follows:

For Methane $\left(\mathrm{CH}_{4}\right)$

$R_{1 a}=\frac{\mathrm{k}_{1 \mathrm{a}} \mathrm{P}_{\mathrm{CH}_{4}} \mathrm{P}_{\mathrm{O}_{2}}^{2}}{\left(1+\mathrm{K}_{\mathrm{CH}_{4}} \mathrm{P}_{\mathrm{CH}_{4}}+\mathrm{K}_{\mathrm{O}_{2}} \mathrm{P}_{\mathrm{O}_{2}}^{2}\right)^{2}}$

$\mathrm{R}_{1 b}=\mathrm{k}_{1 \mathrm{~b}} \mathrm{P}_{\mathrm{CH}_{4}} \mathrm{P}_{\mathrm{H}_{2} \mathrm{O}}\left[1-\frac{\mathrm{P}_{\mathrm{CO}} \mathrm{P}_{\mathrm{H}_{2}}^{3}}{\mathrm{~K}_{1 \mathrm{~b}} \mathrm{P}_{\mathrm{CH}_{4}} \mathrm{P}_{\mathrm{H}_{2} \mathrm{O}}}\right]$

$\mathrm{R}_{1 \mathrm{c}}=\mathrm{k}_{1 \mathrm{c}} \mathrm{P}_{\mathrm{CH}_{4}} \mathrm{P}_{\mathrm{CO}_{2}}\left[1-\frac{\mathrm{P}_{\mathrm{CO}_{2}}^{3} \mathrm{P}_{\mathrm{H}_{2}}^{2}}{\mathrm{~K}_{1 \mathrm{c}} \mathrm{P}_{\mathrm{CH}_{4}} \mathrm{P}_{\mathrm{CO}_{2}}}\right]$

For Ethylene $\left(\mathrm{C}_{2} \mathrm{H}_{4}\right)$

$\mathrm{R}_{2 \mathrm{a}}=\frac{\mathrm{k}_{2 \mathrm{a}} \mathrm{P}_{\mathrm{C}_{2} \mathrm{H}_{4}} \mathrm{P}_{\mathrm{O}_{2}}^{2}}{\left(1+\mathrm{K}_{\mathrm{CH}_{4}} \mathrm{P}_{\mathrm{CH}_{4}}+\mathrm{K}_{\mathrm{O}_{2}} \mathrm{P}_{\mathrm{O}_{2}}^{2}\right)^{2}}$

$\mathrm{R}_{2 \mathrm{~b}}=\mathrm{k}_{2 \mathrm{~b}} \mathrm{P}_{\mathrm{C}_{2} \mathrm{H}_{4}} \mathrm{P}_{\mathrm{H}_{2} \mathrm{O}}^{2}\left[1-\frac{\mathrm{P}_{\mathrm{CO}} \mathrm{P}_{\mathrm{H}_{2}}^{3}}{\mathrm{~K}_{2 \mathrm{~b}} \mathrm{P}_{\mathrm{CH}_{4}} \mathrm{P}_{\mathrm{H}_{2} \mathrm{O}}^{2}}\right]$

$\mathrm{R}_{2 \mathrm{c}}=\mathrm{k}_{2 \mathrm{c}} \mathrm{P}_{\mathrm{C}_{2} \mathrm{H}_{4}} \mathrm{P}_{\mathrm{CO}_{2}}^{2}\left[1-\frac{\mathrm{P}_{\mathrm{CO}}^{4} \mathrm{P}_{\mathrm{H}_{2}}^{2}}{\mathrm{~K}_{2 \mathrm{c}} \mathrm{P}_{\mathrm{C}_{2} \mathrm{H}_{4}} \mathrm{P}_{\mathrm{CO}_{2}}^{2}}\right]$

For Ethane $\left(\mathrm{C}_{2} \mathrm{H}_{6}\right)$

$\mathrm{R}_{3 \mathrm{a}}=\frac{\mathrm{k}_{2 \mathrm{a}} \mathrm{P}_{\mathrm{C}_{2} \mathrm{H}_{6}} \mathrm{P}_{\mathrm{O}_{2}}^{3.5}}{\left(1+\mathrm{K}_{\mathrm{C}_{2} \mathrm{H}_{6}} \mathrm{P}_{\mathrm{C}_{2} \mathrm{H}_{6}}+\mathrm{K}_{\mathrm{O}_{2}} \mathrm{P}_{\mathrm{O}_{2}}^{3.5}\right)^{2}}$

$\mathrm{R}_{3 \mathrm{~b}}=\mathrm{k}_{3 \mathrm{~b}} \mathrm{P}_{\mathrm{C}_{2} \mathrm{H}_{6}} \mathrm{P}_{\mathrm{H}_{2} \mathrm{O}}^{2}\left[1-\frac{\mathrm{P}_{\mathrm{CO}}^{2} \mathrm{P}_{\mathrm{H}_{2}}^{5}}{\mathrm{~K}_{3 \mathrm{~b}} \mathrm{P}_{\mathrm{C}_{2} \mathrm{H}_{6}} \mathrm{P}_{\mathrm{H}_{2} \mathrm{O}}^{2}}\right]$

$\mathrm{R}_{3 \mathrm{c}}=\mathrm{k}_{3 \mathrm{c}} \mathrm{P}_{\mathrm{C}_{2} \mathrm{H}_{6}} \mathrm{P}_{\mathrm{CO}_{2}}^{2}\left[1-\frac{\mathrm{P}_{\mathrm{CO}}^{4} \mathrm{P}_{\mathrm{H}_{2}}^{3}}{\mathrm{~K}_{3 \mathrm{c}} \mathrm{P}_{\mathrm{C}_{2} \mathrm{H}_{6}} \mathrm{P}_{\mathrm{CO}_{2}}^{2}}\right]$
The changes in the components $\mathrm{CH}_{4}, \mathrm{C}_{2} \mathrm{H}_{4}, \mathrm{C}_{2} \mathrm{H}_{6}$, $\mathrm{CO}, \mathrm{CO}_{2}, \mathrm{H}_{2} \mathrm{O}$ and $\mathrm{O}_{2}$ along the reactor length are given by equations 8 and 9 respectively:

$$
\begin{aligned}
& \frac{d F_{i}}{d z}=\rho_{c a t} A_{c a t} \sum_{j} v_{i j} R_{j} \\
& \text { For } \mathrm{O}_{2}, \\
& \frac{d O_{2}}{d z}=\rho_{c a t} A_{c a t}\left[\begin{array}{c}
(-2) R_{1 a}+ \\
(-3) R_{2 a}+(-3.5) R_{3 a}
\end{array}\right]
\end{aligned}
$$

\section{Experimental data and modelling details}

The experimental data from [16] was taken for verifying the proposed kinetic scheme of oxidative coupling of methane. For this study, the reactor is assumed to be essentially a plug flow system (Figure 1) where species concentrations in the radial direction and diffusion of energy and species in the axial direction are assumed to be negligible. The properties of $\mathrm{Mg}-\mathrm{Ti}$ mixed oxide-supported $\mathrm{Na} / \mathrm{W} / \mathrm{Mn}$ catalysts were considered. The modeling operating conditions and reactor configurations are presented in Table 1.

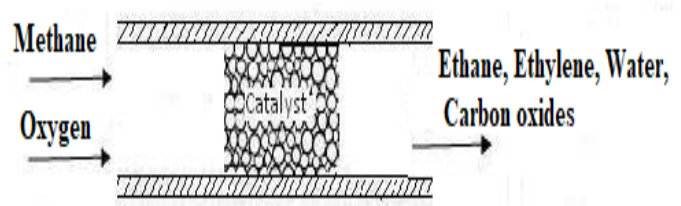

Figure 1 Fixed bed reactor scheme

Table 1 Operating conditions and reactor configuration

\begin{tabular}{ll}
\hline Pressure inside reactor $[\mathrm{ATM}]$ & 1 \\
Methane flow rate $[\mathrm{mol} / \mathrm{s}]$ & 1.45 \\
Catalyst Density $\left[\mathrm{g} / \mathrm{m}^{3}\right]$ & 2355.2 \\
Bed Porosity & 0.3 \\
Length of reactor $[\mathrm{m}]$ & 1 \\
Internal radius of tube $[\mathrm{m}]$ & 0.1 \\
\hline
\end{tabular}

The LH reaction mechanism was considered for developing rate Equations 4, 5 and 6. Equations 7 and 8 were used in the model for accounting the changes of component flow rates along the reactor length. For accounting the oxygen permeation, equations described by [17] were used. In the proposed model, the detailed reaction mechanism, and components and radicals' interactions were considered. A comprehensive time-independent, one-dimensional pseudo-homogeneous simulation model was solved by numerical integration of differentials Equation sets 4,5 and 6 using an explicit Runge-Kutta formula. The kinetic data of the reactions involved were estimated using linear regression. 


\section{Results and discussion}

The basic advantage of using this plug flow type reactor was to allow the combustion of methane throughout the length of the reactor, not letting it to occur only at the beginning of the reactor, which would otherwise damage the reactor due to temperature build up caused by the exothermic nature of the reaction.

The sensitivity of the proposed model towards the changes in inlet conditions was analyzed. The simulation model was studied for various inlet conditions like reactor length, reactor temperature and methane flow rate.

The simulation was run at reactor temperature of $850^{\circ} \mathrm{C}$, for giving methane flow rate and reactor length of 1 meter. The changes of component flow rates predicted by the model along the length of the reactor are given in Figure 2. From model predictions, it was observed that Methane conversion followed a steep linear decline towards the middle of the reactor. The ethylene and ethane production were higher in the middle of the reactor. It was also observed that the component flow rates were stabilized towards the end of the reactor.

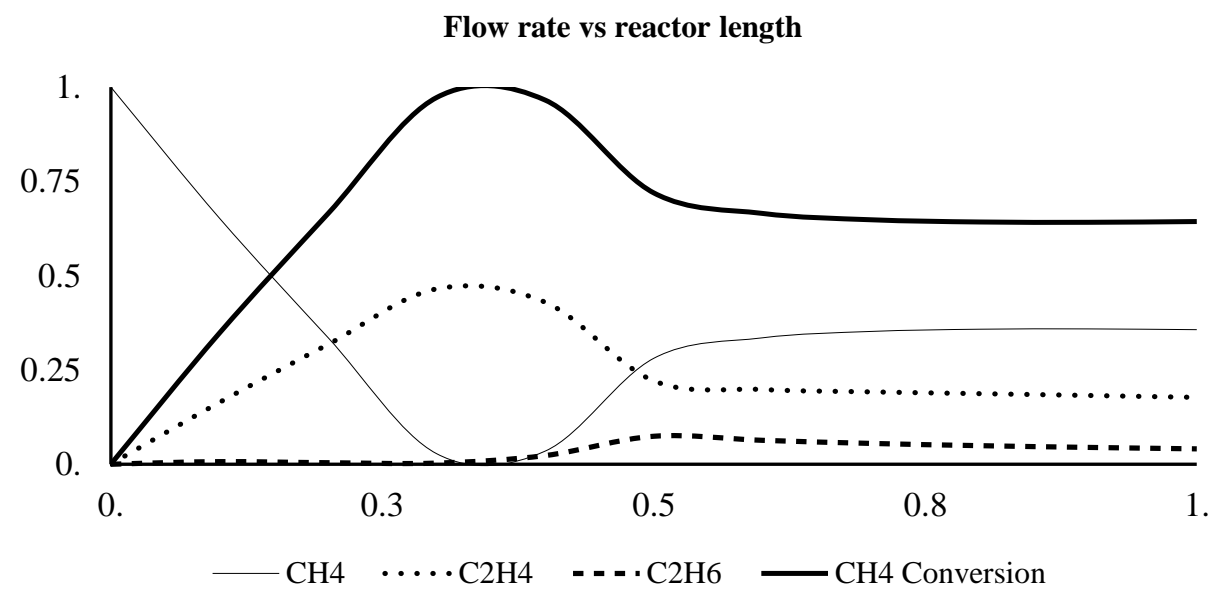

Figure 2 Changes in flow rates $\left(\mathrm{gmol} / \mathrm{sec}\right.$ ) of the components $\mathrm{CH}_{4}, \mathrm{C}_{2} \mathrm{H}_{4}, \mathrm{C}_{2} \mathrm{H}_{6}$ along the reactor length (meter) at a temperature of $850^{\circ} \mathrm{C}$ for $\mathrm{Mg}-\mathrm{Ti}$ mixed oxide-supported $\mathrm{Na} / \mathrm{W} / \mathrm{Mn}$ catalysts

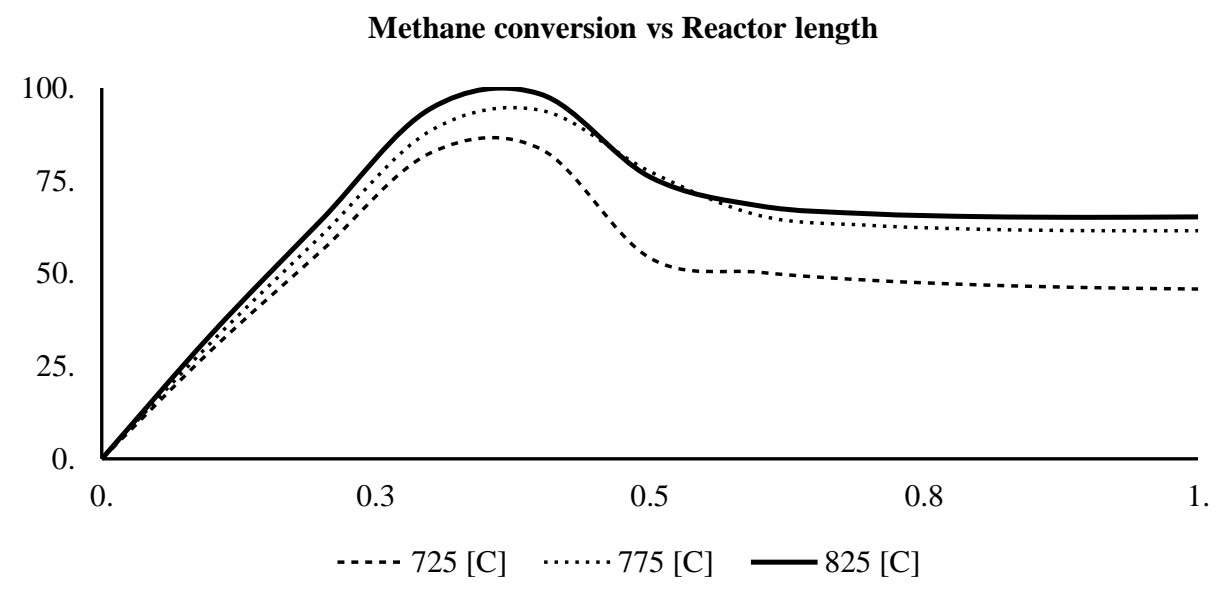

Figure 3 Methane conversions (\%) studied along the length of the reactor (meter) at different temperatures ranging from $725^{\circ} \mathrm{C}$ to $825^{\circ} \mathrm{C}$ for $\mathrm{Mg}-\mathrm{Ti}$ mixed oxide-supported $\mathrm{Na} / \mathrm{W} / \mathrm{Mn}$ catalysts 
Methane conversion, $\mathrm{C}_{2} \mathrm{H}_{4}$ and $\mathrm{C}_{2} \mathrm{H}_{6}$ were studied along the length of the reactor at different temperatures. The simulation was run at reactor temperature of 725,775 and $825^{\circ} \mathrm{C}$ for the same reactor configuration and other operating conditions. Temperature played a vital role in OCM through catalytic reactors. Higher temperatures enhanced Methane conversions (Figure 3). As the operating temperature increased the maximum conversion point moved away from the reactor entrance, thus ensuring combustion for a longer distance away from the reactor.
The products $\mathrm{C}_{2} \mathrm{H}_{4}$ and $\mathrm{C}_{2} \mathrm{H}_{6}$ flow rates predicted by the model along the length of the reactor at different temperatures are given in Figure $4 \&$ Figure 5 . High ethylene and ethane are produced at lower temperatures and farther to the reactor entrance. An increase in the reactor temperature allows higher production of ethylene and ethane up to a longer distance from the reactor entrance, ensuring that combustion of methane is spread for a greater length of the reactor.

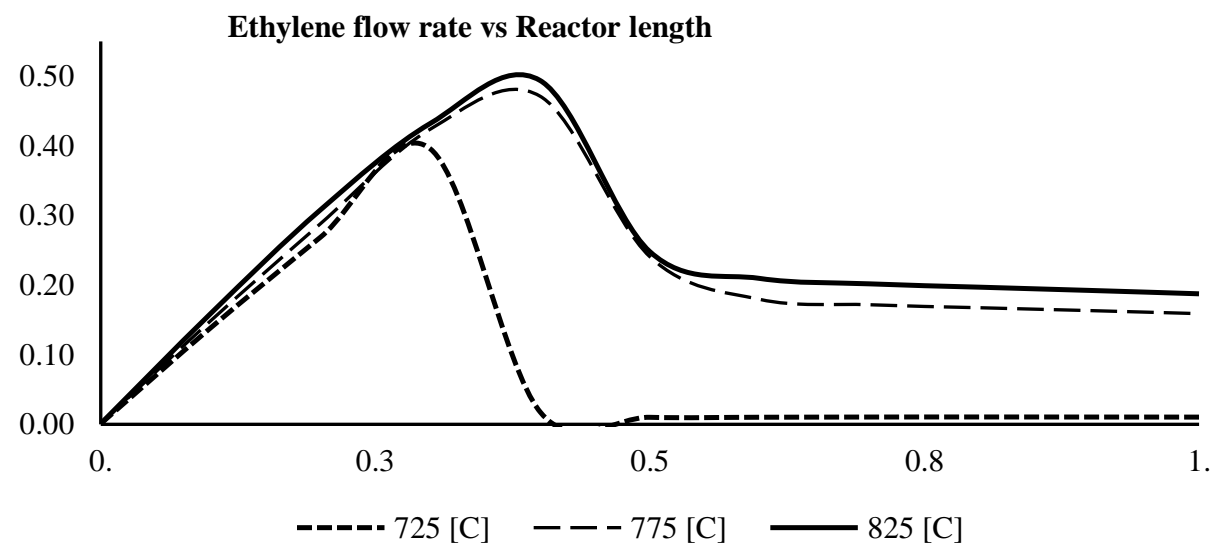

Figure 4 Product (ethylene) flow rates (gmol/sec) studied along the length of the reactor (meter) at different temperature

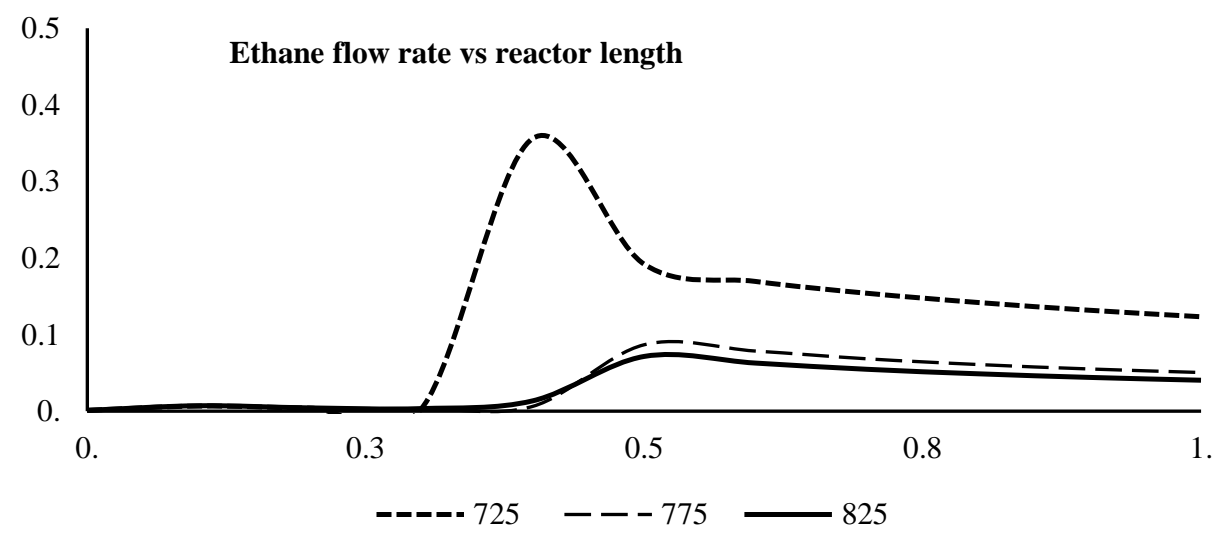

Figure 5 Product (ethane) flow rates studied along the length of the reactor at different temperatures 


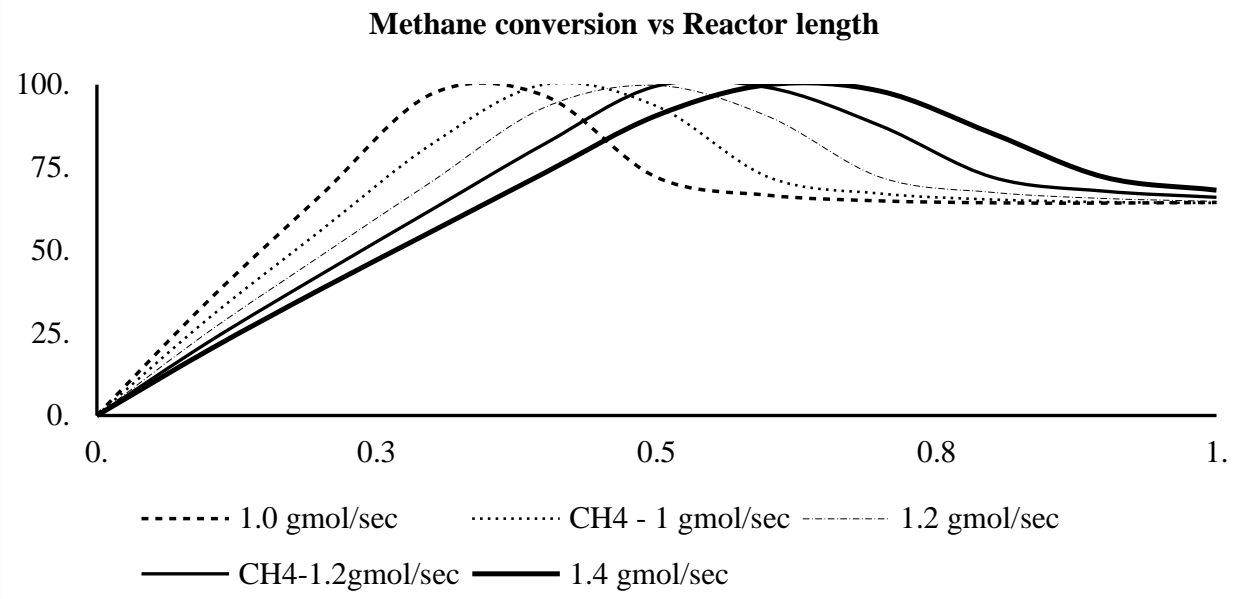

Figure 6 Effect of methane flow rate $(\mathrm{gmol} / \mathrm{sec})$ on its conversion studied along the length of the reactor (meter)

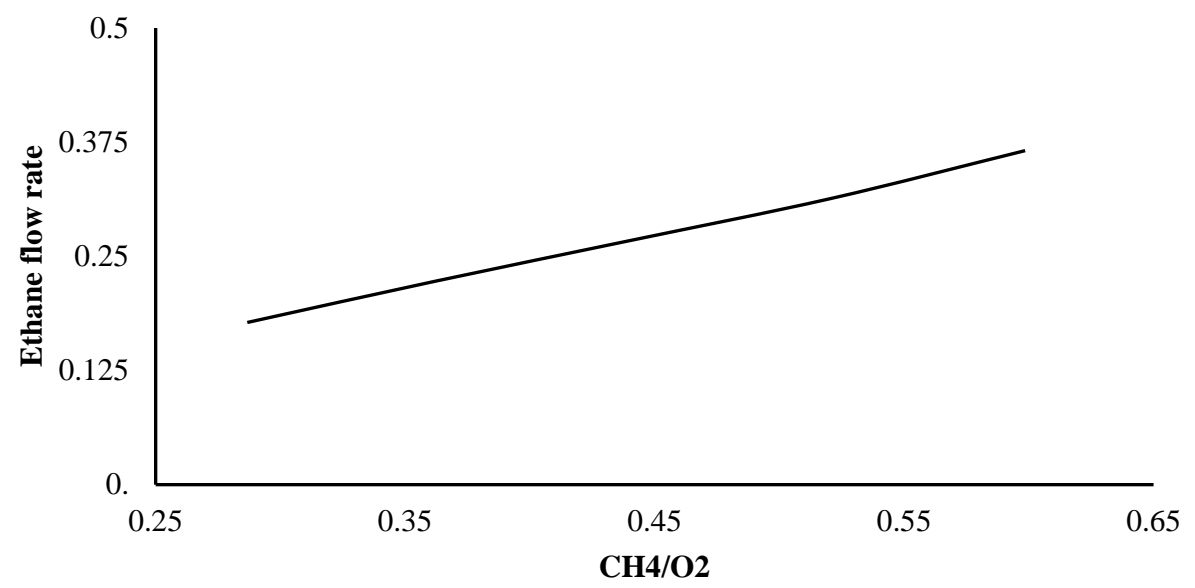

Figure 7 Effect of methane to the oxygen ration of ethane flow rate studied along the length of the reactor

Effect of methane flow rate on methane conversion (Equation 9) was studied along the length of the reactor (Figure 6). The simulation was run at same reactor temperatures of $850^{\circ} \mathrm{C}$ for the same reactor configuration and other operating conditions as mentioned in Table1, by varying methane flow rate. Higher methane conversions were observed for higher methane feed flow rates. Therefore, the reactor length, temperature and feed flow rates play a vital role in determining the optimum methane conversion. Production of ethane (Figure 7) also increases linearly with the increase in methane to oxygen ratio, indicating the effectiveness of the reactor in supplying oxygen to the reaction. Hence recycle of reactants can be minimized.

\section{Comparison with experimental data for model validation}

A comparison with the literature of the reaction kinetics data was conducted to demonstrate the validity of the proposed kinetic model. The results from the proposed model were in agreement with experimental data (Table 2) published by Jeon [16]. The $\mathrm{C}_{2}$ yield (equation 11) and $\mathrm{C}_{2} \mathrm{H}_{4} / \mathrm{C}_{2} \mathrm{H}_{6}$ comparison is shown in Figure 8 and Figure 9.

The proposed kinetic model in a temperature range of $725-850^{\circ} \mathrm{C}$ showed deviations of the experimental data, but the trend is followed by the model. The kinetic model proposed is a 1D-pseudo-homogeneous model. 
The difference between model predictions and experimental data may be attributed to the fact that mass transfer limitations inside the catalyst particles and across the radius of the reactor were neglected. Figure 8 indicates that $\mathrm{C}_{2} \mathrm{H}_{4} / \mathrm{C}_{2} \mathrm{H}_{6}$ molar ratio increases with the increase in the reactor temperature between the $750-800^{\circ} \mathrm{C}$ and further increase the temperature does not affect the ratio as the curve gets flattened. This is because the reactions which produce ethylene and ethane are many promising than those which prevent them from increasing this ratio.

Initially $\mathrm{C}_{2}$ increases with increasing temperature. But a further increase in temperature beyond $825^{\circ} \mathrm{C}$ exhibits a decreasing trend (Figure 9), as the temperature influences the progress of the reactions. At low temperatures, the reactions which cause increased the yield (such as reaction 1a) are faster than the others while at higher temperatures they become slower than others reactions. This is attributed to the fact that the reactions with higher activation energy, accelerate more than those with a lower activation energy. In the reaction network shown above, reversible reactions $2 \mathrm{~b}, 2 \mathrm{c}, 3 \mathrm{~b}$ and $3 \mathrm{c}$ has the highest activation energy. These reactions consume ethylene, ethane and cause a decrease in the yield.

Table 2 Comparison of model predictions and experimental data

\begin{tabular}{|c|c|c|}
\hline \multirow[t]{2}{*}{ Reactor temperature $\left[{ }^{0} \mathrm{C}\right]$} & \multicolumn{2}{|c|}{$\mathrm{C}_{2} \mathrm{H}_{4} / \mathrm{C}_{2} \mathrm{H}_{6}$} \\
\hline & Experimental & Model \\
\hline 725 & 0.05 & 0.08 \\
\hline 750 & 0.67 & 2.02 \\
\hline 775 & 2.27 & 3.15 \\
\hline 800 & 3.07 & 4.16 \\
\hline 825 & 3.22 & 4.65 \\
\hline 850 & 3.24 & 4.33 \\
\hline \multirow{2}{*}{ Reactor Temperature $\left[{ }^{\circ} \mathrm{C}\right]$} & \multicolumn{2}{|c|}{$\mathrm{C}_{2}$ Yield , [\%] } \\
\hline & Experimental & Model \\
\hline 725 & 2.50 & 26.70 \\
\hline 750 & 10.20 & 37.40 \\
\hline 775 & 15.30 & 41.86 \\
\hline 800 & 18.20 & 44.78 \\
\hline 825 & 18.90 & 45.54 \\
\hline 850 & 17.40 & 43.70 \\
\hline
\end{tabular}

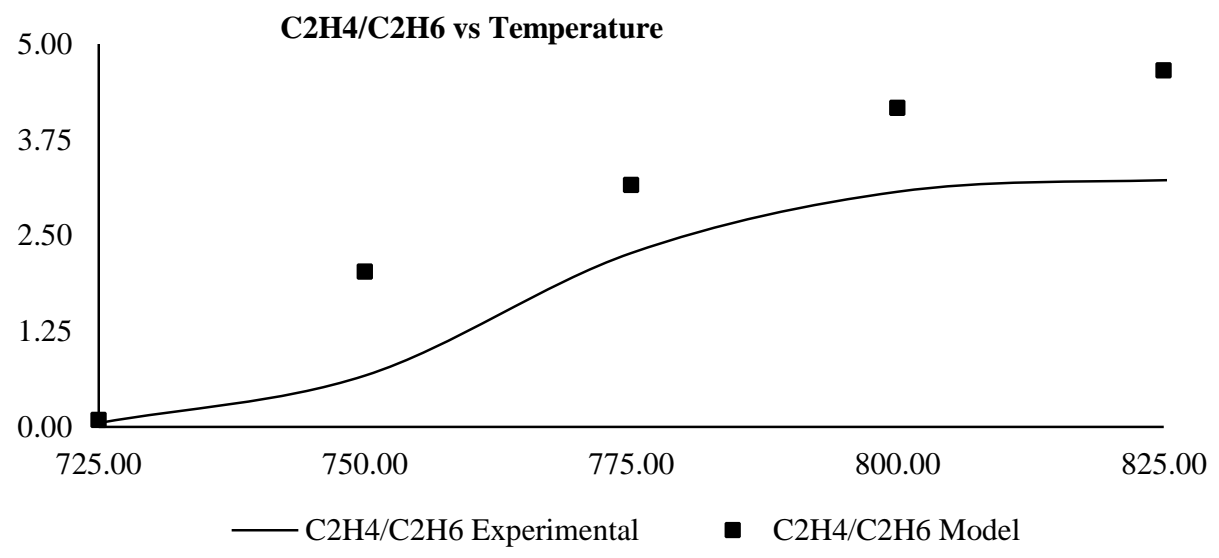

Figure 8 Comparison of $\mathrm{C}_{2} \mathrm{H}_{4} / \mathrm{C}_{2} \mathrm{H}_{6}$ experimental and model generated values at various temperatures 


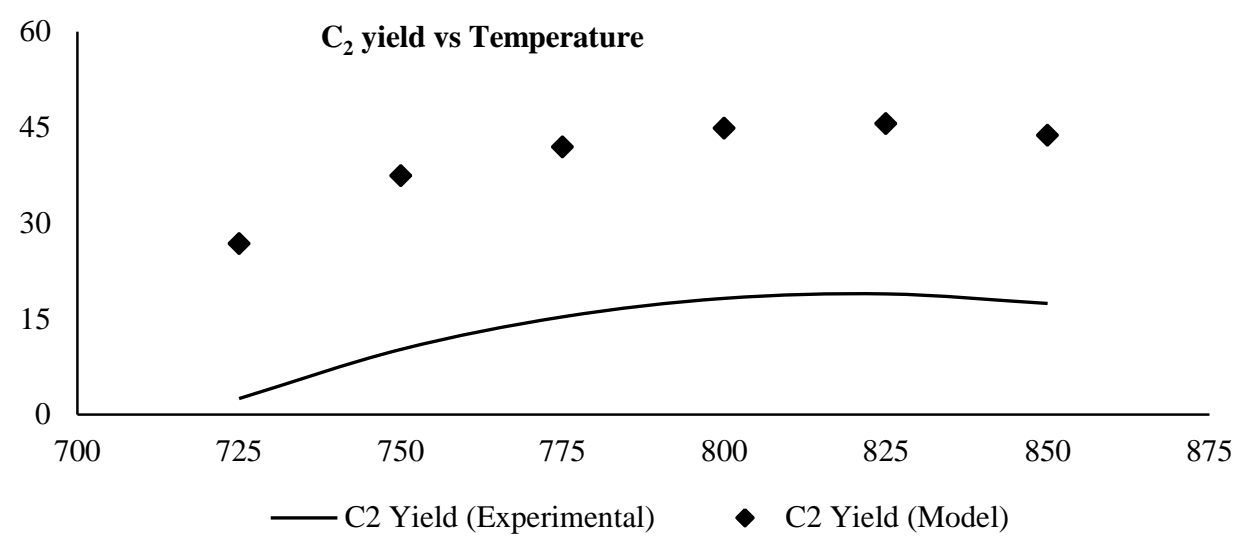

Figure 9 Comparison of $\mathrm{C}_{2}$ yield (Experimental and model) at various temperatures

\section{Conclusions and future suggestions}

An isothermal model was developed considering a nine-step reaction mechanism whose kinetics has been described based on LH mechanism. The predictions from the model suggested that the methane flow rates, reactor length and temperature of reaction have a key role in determining the extent of reaction. The major setback with the available kinetic models in literature is that they considered only primary reactions leading to the desired products. A comprehensive kinetic model is proposed which accounted all the possible kinetics that influences the reactions. It is suggested that the proposed LH kinetic model can be used for estimating the methane conversion, $\mathrm{C}_{2}$ yield under the same conditions. The trends illustrating the experimental data of $\mathrm{C}_{2}$ yield and $\mathrm{CH}_{4}$ conversion agreed reasonably well with the model predictions. It is also noted that $725-825^{\circ} \mathrm{C}$ is the temperature range applicable to achieve maximum yields. This can be obtained by careful control of oxygen flow rate, which would eventually minimize the side effects of high temperatures. The measured methane conversion, and yields of ethylene, ethane was predicted with a relative error of less than $\pm 20 \%$. The accuracy of the model predictions shows that the LH model is about predicting OCM performance over a wide range of operating conditions. It is suggested that:

- Researchers can use this model in computer aided design and reactor simulations.

- This kinetic model may be used as a generic one for the fixed bed catalytic reactors with OCM catalysts, with similar properties for studying the reaction parameters and sensitivity.

- Runge Kutta method was used to solve numerical integration in this study to solve the model 99 equations. It is suggested that genetic algorithm, artificial neural network can also be used to simulate the results and test the sensitivity of the model

\section{Acknowledgment}

None.

\section{Conflicts of interest}

The authors have no conflicts of interest to declare.

\section{References}

[1] Lunsford JH. Catalytic conversion of methane to more useful chemicals and fuels: a challenge for the 21st century. Catalysis Today. 2000; 63(2-4):165-74.

[2] Ross JR, Van Keulen AN, Hegarty ME, Seshan K. The catalytic conversion of natural gas to useful products. Catalysis Today. 1996; 30(1-3):193-9.

[3] Keller GE, Bhasin MM. Synthesis of ethylene via oxidative coupling of methane: i. determination of active catalysts. Journal of Catalysis. 1982; 73(1):919.

[4] Akin FT, Lin YS. Controlled oxidative coupling of methane by ionic conducting ceramic membrane. Catalysis Letters. 2002; 78(1-4):239-42.

[5] Wang W, Lin YS. Analysis of oxidative coupling of methane in dense oxide membrane reactors. Journal of Membrane Science. 1995; 103(3):219-33.

[6] Wang K, Ji S, Shi X, Tang J. Critical influence of $\mathrm{BaCO}_{3}$ on low temperature catalytic activity of $\mathrm{BaCO}_{3} / \mathrm{ZrO}_{2}$ catalysts for oxidative coupling of methane. Catalysis Letters. 2009; 129(1-2):156-62.

[7] Stansch Z, Mleczko L, Baerns M. Comprehensive kinetics of oxidative coupling of methane over the $\mathrm{La}_{2} \mathrm{O}_{3} / \mathrm{CaO}$ catalyst. Industrial \& Engineering Chemistry Research. 1997; 36(7):2568-79.

[8] Simon Y, Baronnet F, Marquaire PM. Kinetic modeling of the oxidative coupling of methane. 
Industrial \& Engineering Chemistry Research. 2007; 46(7):1914-22.

[9] Sun J, Thybaut JW, Marin GB. Microkinetics of methane oxidative coupling. Catalysis Today. 2008; 137(1):90-102.

[10] Farsi A, Moradi A, Ghader S, Shadravan V, Manan ZA. Kinetics investigation of direct natural gas conversion by oxidative coupling of methane. Journal of Natural Gas Science and Engineering. 2010; 2(5):270-4.

[11] Sinev MY, Fattakhova ZT, Lomonosov VI, Gordienko YA. Kinetics of oxidative coupling of methane: bridging the gap between comprehension and description. Journal of Natural Gas Chemistry. 2009; 18(3):273-87.

[12] Shahri SM, Alavi SM. Kinetic studies of the oxidative coupling of methane over the $\mathrm{Mn} / \mathrm{Na}_{2} \mathrm{WO}_{4} / \mathrm{SiO}_{2}$ catalyst. Journal of Natural Gas Chemistry. 2009; 18(1):25-34.

[13] Cheng S, Shuai X. Simulation of a catalytic membrane reactor for oxidative coupling of methane. AIChE Journal. 1995; 41(6).

[14] Yaghobi N, Ghoreishy MH. Oxidative coupling of methane in a fixed bed reactor over perovskite catalyst: a simulation study using experimental kinetic model. Journal of Natural Gas Chemistry. 2008; 17(1):8-16.

[15] Santamaria JM, Miro EE, Wolf EE. Reactor simulation studies of methane oxidative coupling on a sodium/nickel-titanium oxide $\left(\mathrm{NiTiO}_{3}\right)$ catalyst. Industrial \& Engineering Chemistry Research. 1991; 30(6):1157-65.
[16] Jeon W, Lee JY, Lee M, Choi JW, Ha JM, Suh DJ, et al. Oxidative coupling of methane to $\mathrm{C}_{2}$ hydrocarbons on the mg-ti mixed oxide-supported catalysts at the lower reaction temperature: role of surface oxygen atoms. Applied Catalysis A: General. 2013; 464:6877.

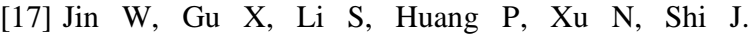
Experimental and simulation study on a catalyst packed tubular dense membrane reactor for partial oxidation of methane to syngas. Chemical Engineering Science. 2000; 55(14):2617-25.

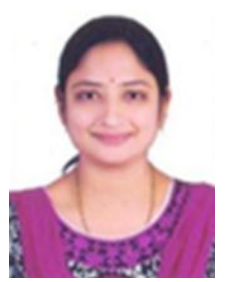

Mrs. Kalyani Miriyala is a Masters Graduate in Chemical Engineering from Cleveland State University, USA and working as an Assistant Professor in CBIT, Hyderabad. Currently pursuing part time $\mathrm{PhD}$ at JNTUACE, Anantapuramu.

Email: miriyala.kalyani@gmail.com

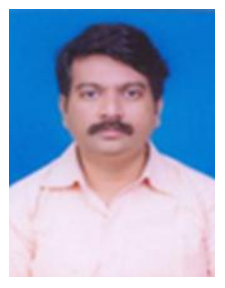

Mr. Bala Krishna Inguva is a Masters graduate in Chemical Engineering from Osmania University College of Technology, Hyderabad and working as a Senior Assistant Professor in CBIT, Hyderabad. Currently pursuing part time $\mathrm{PhD}$ at JNTUACE, Anantapuramu. 